\title{
EL SOCIALISMO CABETIANO: LA HERENCIA UTÓPICA DE MORO EN LA ESPAÑA DEL SIGLO XIX ${ }^{1}$
}

\author{
Matteo Parisi \\ (Universidad Autónoma de Madrid)
}

\section{RESUMEN:}

En 1840 se publica Voyage en Icarie una obra que revela uno de los proyectos de socialismo utópico más importantes del siglo XIX. Su autor, Étienne Cabet, probablemente se había inspirado en la lectura de Utopía de Tomás Moro. Esta lectura produjo en el político francés tal impresión que decidió cambiar totalmente su estrategia política. A los pocos años de la primera edición del Viaje a Icaria, un grupo de republicanos catalanes emprende la publicación por entregas de esta obra en el periódico La Fraternidad, y empieza a difundir las ideas de Cabet a través de la publicación de los artículos de Le Populaire. Es el inicio del grupo cabetiano más importante fuera de Francia. El objetivo de este texto es analizar el legado que Moro tuvo en el proyecto utópico de Cabet para ver, efectivamente, que propuestas del político inglés seguían siendo actuales a los ojos de los pensadores utópicos del siglo XIX; sobre todo a la luz del interés que despertó la propuesta utópica cabetiana en el contexto político español.

PALABRAS CLAVE: comunismo icariano, Étienne Cabet, Utopía, Tomás Moro, Monturiol

\section{CABETIAN SOCIALISM: MORE'S UTOPIAN HERITAGE IN NINETEENTH-CENTURY SPAIN}

\begin{abstract}
Voyage en Icarie was published in 1840, this is a book that reveals one of the most important utopian's projects of the 19th century. His author, Étienne Cabet, was influenced by More's Utopia in such a manner that he decided to change completely

${ }^{1}$ Este trabajo se ha realizado en el marco del proyecto HAR2015-65957-P del Plan Nacional de I+D+i MINECO-FEDER (Historia del futuro: la utopía y sus alternativas en los horizontes de expectativa del mundo contemporáneo, siglos XIX-XXI).
\end{abstract}


his political strategy. A few years after the publication of The Voyage to Icaria's first edition, a group of Catalans Republicans decided to publish this book in Spanish in the weekly newspaper La Fraternidad. They also started to propagate Cabet's ideas through the publication of articles of the newspaper Le Populaire. This is the beginning of the most important icarian group out of France. The purpose of this text is to investigate More's legacy for this utopian project, and find out which proposals of the English chancellor could be valid for a utopian thinker of the 19th century, mainly due to the interest aroused by the icarian proposal in Spain.

KEYWORDS: icarian communism, Étienne Cabet, Utopia, Thomas More, Monturiol.

$* * *$

\section{INTRODUCCIÓN}

De las tres corrientes principales del socialismo utópico francés sansimonismo, furierismo y comunismo icariano- esta última es la que más evidencia sus lazos con Utopía de Moro. Estas tres corrientes, junto con el owenismo, son los principales objetivos de los ataques de Marx y Engels que -en su definición de socialismo utópico- añaden una acepción negativa del término utópico, en oposición a lo científico ${ }^{2}$. Engels subraya sobre todo el carácter prematuro de estas doctrinas, productos del contexto histórico en el que se desarrollan: surgen en una etapa de transición, en la que el capitalismo industrial es aún incipiente y apenas está desarrollado. El socialismo utópico, según el pensador alemán, a pesar de la bondad de las ideas desarrolladas, faltaba de las condiciones sociales y materiales para que se realizara: elemento que el socialismo científico intenta solucionar.

Como indica Maluquer ${ }^{3}$, es importante recordar que el marxismo considera las utopías un pensamiento ingenuo y poco desarrollado, pero no como unas ideas necias: es preciso que existan hombre y grupos sociales que posean estas ideas con algún objetivo, por irrealizable que sea. Hoy en día, el término utopía sufre de la acepción negativa de la definición marxista, en concreto porque es considerada como una quimera, pero muchas veces nos olvidamos de que Marx y Engels no las consideraban totalmente negativas. De hecho no hay que olvidar que, en La ideología alemana, Marx y Engels "defendieron" a Cabet y su socialismo utópico frente a la interpretación que había dado de él Karl Grün, en su volumen sobre los movimientos sobre los movimientos sociales en Francia y Bélgica ${ }^{4}$.

\footnotetext{
${ }^{2}$ Friedrich Engels, Del socialismo utópico al socialismo científico: Ludwig Feuerbach y el fin de la filosofía clásica alemana (San Sebastián: Equipo Editorial, 1968).

${ }^{3}$ Jordi Maluquer de Motes, El socialismo en España 1833-1868 (Barcelona: Crítica, 1977), 17.

${ }^{4}$ Karl Marx y Friedrich Engels, La ideología alemana (Montevideo: Pueblos Unidos, 1968), 630-646.
} 
El punto de partida de este estudio parte de una lectura diferente de los conceptos de utopía y socialismo utópico, que se han difundido en la historiografía contemporánea, núcleo central de este tipo de investigaciones es el papel privilegiado que ha desempeñado la utopía en la conformación del mundo moderno, en este caso en el siglo XIX ${ }^{5}$. Siempre citando a Maluquer:

Las utopías particularmente importantes son las fases iniciales de los procesos históricos de formación de nuevas voluntades colectivas. La crítica a los complejos ideológicos dominantes tiende a destruir su estabilidad y contribuye a transformar sus contenidos, su función básica reside, como subraya Gramsci, en convertir en fundamentales los elementos secundarios, subordinados o incidentales, de las ideologías dominantes, y en disolver la vieja mentalidad en sus aspectos más contradictorios. Por eso mismo las utopías se constituyen en fuerzas motrices de un más profundo análisis de la realidad y de una renovada actividad política colectiva ${ }^{6}$.

El objetivo de este texto es analizar la influencia que ha tenido el texto de Tomás Moro en la publicación del Voyage en Icarie y en la trayectoria política de Cabet, teniendo en cuenta el éxito que han tenido las doctrinas icarianas en España y su influencia en la fundación del partido demócrata español. Para lograr este objetivo resulta fundamental examinar la biografía de Cabet, sobre todo para entender el papel que ha conllevado su periodo de exilio en Londres, donde se supone leerá por primera vez la obra de Moro. En la segunda parte del texto, el análisis se centra en el estudio de la génesis del grupo cabetiano español, para entender el impacto de las doctrinas icarianas en España. En el tercer apartado, se resume el experimento de fundar una comunidad de bienes, intentado por los icarianos en Estados Unidos. Este breve recorrido permitirá entender mejor las dificultades que ha encontrado la aplicación práctica de diseños utópicos, como el de Moro y el de Cabet. Por último, el estudio tiene como objetivo ilustrar el contenido del Voyage, con el fin de plantear una comparación entre estas dos obras, dentro del panorama de textos utópicos que se considerarían fuente de inspiración para el abogado francés.

\section{ÉTIENNE CABET}

Cabet nació en Dijon en 1788 en una familia de pequeños artesanos ${ }^{7}$. Además de frecuentar el lycée, el joven Étienne ayudaba al padre en la empresa de tonelería familiar. En mayo de 1812, completó sus estudios en la Facultad de Derecho, donde pudo conocer a Victor Proudhon, un primo lejano del célebre Pierre-Joseph, que era

${ }^{5}$ En la definición que da Arnhelm Neusüss (Utopía, Barcelona: Barral, 1971) la utopía se divide en tres tipologías: utopía como fenómeno literario, como antigua fase del pensamiento sociológico (precientífico según Engels) y como anticipación del futuro. el punto de partida de este estudio se centra sobre todo en este tercer tipo.

${ }^{6}$ Maluquer, El socialismo en España, 21.

7 Para una biografía más completa sobre Etienne Cabet ver: Jules Prudhommeaux, Icarie et son fondateur Etienne Cabet (Ginebra: Slatkine-Megariotis Reprints, 1977). 
el decano de la facultad y que tuvo una gran influencia en las ideas republicanas de Cabet.

Su afán por entrar en la vida política francesa le llevó a trasladarse a París en 1820, donde comenzó a trabajar en un importante bufete de abogados de la ciudad. En la capital, empezó a colaborar con la Carbonería y a escribir sus primeros textos de carácter político. Favorecido por la llegada al poder de Luis Felipe, a pesar de sus críticas contra la monarquía de Julio, Cabet fue nombrado Procurador General de Córcega en 1830. Al año siguiente fue elegido diputado de la Côte d'Ôr y se traslada de nuevo a París.

En 1832, publicó su primer libro, Historia de la Revolución de 1830, que intenta ser una crónica objetiva de la Revolución de Julio, del ascenso de Luis Felipe y de los objetivos principales del levantamiento, los cuales el Duque de Orleans no llegó a cumplir nunca. El éxito de su primera obra permitió a Cabet despegar en su carrera política: como presidente del Comité de la Asociación para la libertad de prensa publicó numerosos folletos sobre la censura de los periódicos republicanos y colaboró activamente con la Asociación libre para la educación del pueblo, tanto como redactor y editor del periódico de la Asociación, Le Fondateur.

A partir de su primera experiencia como editor, Cabet decidió fundar un nuevo periódico para promover la divulgación de posibles reformas; tales como el sufragio universal, la igualdad frente a la ley, etc.: nació así Le Populaire. Esta publicación le ocasionó problemas con la ley, pues en 1834, dos artículos publicados en su periódico, con duras críticas a Luis Felipe, provocaron que fuera imputado en los tribunales acusado de sedición, crimen punible con una multa de hasta diez mil francos y cinco años de cárcel.

Cuando se celebró el juicio, Cabet fue declarado culpable y sentenciado a dos años en prisión y una multa de cuatro mil cuatrocientos francos. Cabet quería aceptar la sentencia inicial, pero sus abogados le aconsejaron conmutar la pena por cinco años de exilio, prometiendo enviarle dinero para su manutención. Según Sutton, el objetivo real de sus compañeros era alejarlo de la vida política parisina porque había empezado a ser demasiado atrevido e insolente en sus escritos, lo que provocaba la condena severa de las autoridades y los consecuentes inconvenientes para todo su entorno ${ }^{8}$.

Cabet decidió trasladarse a Londres, donde llegó el 1 de mayo de 1834. Hay muy poca información sobre su estancia en Londres, pero evidentemente fue un periodo de intensa producción ya que escribió sus dos obras principales: Historia Popular de la Revolución Francesa y Viaje por Icaria. Estas dos obras están estrictamente relacionadas ya que Cabet las ideó en el mismo periodo. Mientras la primera explica los objetivos de la Revolución francesa y su parcial realización, la segunda ofrece un

\footnotetext{
${ }^{8}$ Robert P. Sutton, Les icariens: the utopian dream in Europe and America (Chicago: University of Illinois Press, 1994), 15.
} 
plan para cumplir definitivamente los objetivos de esta y establecer la igualdad entre personas. Es curioso como ambas obras consideran imprescindibles para la realización de sus objetivos dos personas con comportamientos típicamente despóticos: Robespierre, el verdadero revolucionario según Cabet, e Icar, el fundador de Icaria.

En 1839, terminado su exilio, Cabet volvió a París, donde publicó el Vyage en Icarie no sin dificultades. No se sabe quién financió la publicación, pero es cierto que el autor recibió varias negativas de amigos y antiguos colaboradores. Está claro que medidas tan radicales, como la abolición de la propiedad privada, fueran mal vistas por parte de muchos moderados, a pesar de que en el pasado estos habían sido cercanos a Cabet. El libro se llamó inicialmente Voyage et aventure de Lord William Carisdall en Icarie, pero para evitar la censura se publicó bajo el seudónimo de Francis Adams, como una traducción por Theodore Dufruit de una supuesta versión en inglés.

En 1841, volvió a publicar también Le Populaire, que ya era oficialmente el «órgano para la reorganización social». La accesibilidad de los artículos de Cabet, junto con un precio muy asequible, hicieron que el periódico cabetiano justificara su nombre, transformándose en uno de las publicaciones más exitosas de la Francia de los años 40. Pero la actividad de Cabet no se limitaba a la publicación del periódico, puesto que también difundía sus doctrinas con folletos y breves opúsculos con éxito, como Le V rai Christianisme suivant Jésus-Christ, publicado en 1846.

El mensaje de Cabet se difundió por todo el país gracias a la red de contactos que logró construir, y pronto el Voyage se tradujo al castellano y al alemán. Según el cálculo de Johnson, en 1846 cerca de cien mil franceses, entre hombres y mujeres, se podrían considerar icarianos y Le Populaire rondaba las tres mil quinientas copias vendida por cada número?

\section{EL GRUPO CABETIANO BARCELONÉS}

La difusión del pensamiento cabetiano en España se limita casi exclusivamente al contexto catalán, lo que se debe principalmente al grupo de Narcís Monturiol. No es de extrañar que Barcelona fuera un campo fértil para la difusión de este tipo de corrientes de pensamiento, ya que en las décadas de los 30 y 40 del siglo XIX era la única ciudad española donde existía un proletariado industrial numeroso. Los primeros textos de Cabet leídos en España eran anteriores a su exilio en Inglaterra y a su conversión al comunismo, como testimonia la publicación de su obra Revolución francesa de 1830 por parte de Abdón Terradas en 1839. Terradas era la figura principal del grupo republicano que operaba en esos años en Barcelona, donde participaba también un joven Monturiol y el núcleo del que será el grupo icariano barcelonés.

\footnotetext{
${ }^{9}$ Christopher H. Johnson, Utopian Communism in France: Cabet and the Icarians, 1839-1851 (Londres: Cornell University Press, 1974), 145.
} 
En realidad, no se puede hablar abiertamente de un grupo icariano español hasta la publicación del periódico La Fraternidad, que salió a la venta desde el mes de noviembre de 1847 hasta marzo de 1848, cuando fue cerrado por las autoridades por el miedo a que se difundieran las ideas revolucionarias francesas ${ }^{10}$. Paralelamente a la publicación de este periódico, el grupo cabetiano barcelonés se encargó también de la publicación del Voyage en Icarie, cuya traducción al castellano en 1848 se debe a Narcís Monturiol y Francisco de Orellana, y sigue siendo la única edición en castellano que se ha publicado hasta ahora.

La publicación periódica del grupo nació como órgano del partido socialista español, pero a partir del número VI se declara explícitamente cabetiana y comienza a predicar las doctrinas icarianas. El periódico se dedicaba a la traducción de artículos de Le Populaire, el periódico de Cabet, y la transcripción de varios fragmentos del Voyage y otros folletos de Cabet. Por ejemplo, en el número VIII del periódico se explica todo lo relativo a la expedición a Estados Unidos para la fundación de una comunidad ideal. Copiando la famosa proclama «Allons on Icarie», Cabet comunica su decisión de perseguir el sueño de Lord William Carisdall, el protagonista del Voyage, que quiere fundar la Comunidad de bienes y convencer la humanidad de la bondad de su proyecto.

La lectura de este periódico nos permite comprender la importancia del grupo barcelonés que, como demuestran los numerosos contactos con los grupos icarianos franceses, era el grupo cabetiano más importante fuera de Francia, junto al grupo alemán. Este interés se demuestra en la participación de Juan Rovira e Ignacio Montaldo en las primeras vanguardias que salen del puerto de El Havre hasta Texas para fundar la comunidad. En concreto, en el caso de Juan Rovira-, se aprecia la involucración del grupo de Monturiol, que ayuda a su compañero a recaudar el dinero necesario para financiar estos viajes, además de ocuparse del mantenimiento de la mujer de Rovira que se encontraba embarazada en el momento de la partida y no pudo acompañar a su marido en la expedición.

El interés del conjunto cabetiano barcelonés era tal que se planteó la organización de una vanguardia que saliera directamente del puerto de Barcelona con el fin de resaltar la importancia de la contribución española a la experiencia icariana. Esta intención seguirá siendo un proyecto efímero, pero demuestra la seriedad de la implicación de Monturiol y su grupo. Inicialmente, varios subscriptores del periódico quisieron participar en las expediciones organizadas por Cabet, pero la mala experiencia de Rovira, que se enfrentó directamente a Cabet y le acusó de incumplir sus propios principios y el elevado coste de admisión, que rondaba los seiscientos francos, fueron elementos disuasorios que limitaron las salidas hacia Icaria. Hay que tener también en cuenta la petición de Narcís Monturiol para ser admitido en la colonia, pero probablemente a causa de los problemas internos en la comunidad su solicitud

${ }^{10}$ El periódico La Fraternidad se encuentra en el Archivo Histórico de la Ciudad de Barcelona donde se conservan 16 de los 18 números publicados, desde noviembre de 1847 hasta marzo de 1848. Después del cierre del periódico, el grupo siguió su actividad con otras publicaciones, aunque no estaban ligadas abiertamente a las doctrinas de Cabet. 
no fue considerada hasta demasiado tarde, cuando el intelectual ampurdanés ya se estaba dedicando a la invención del submarino.

\section{LA REALIZACIÓN DEL SUEÑO UTÓPICO: LA FUNDACIÓN DE ICARIA}

Muchos autores coinciden en que la decisión de Cabet de emprender el proyecto de fundar Icaria fue fruto de sus fracasos en la política francesa y probablemente las cosas habrían sido diferentes si las revoluciones de 1848 hubieran tenido un resultado diferente. A pesar de estas dudas, en 1848, Cabet decidió ceder a las presiones de buena parte de sus secuaces para organizar la expedición para fundar Icaria. Cabet comunica su decisión en mayo de 1847, con el artículo «Allons on Icarie» publicado en Le Populaire ${ }^{11}$ y traducido para La Fraternidad a finales de año. Es probable que varios problemas que estaban teniendo los diferentes grupos icarianos en Francia hayan contribuido a esta decisión.

Con el fin de poder organizar la expedición, Cabet se puso en contacto con William Peters, gracias a la intermediación de Robert Owen. Peters ofreció a Cabet una oportunidad que no podía rechazar: la posibilidad de ocupar un territorio de Texas ideal para fundar una nueva comunidad. Supuestamente era un territorio fértil, muy cerca del río Trinity, con un clima ideal para el cultivo y fácilmente accesible para barcos y otros medios de transporte. Después de una breve reunión entre Cabet, Owen y Peters en septiembre de 1847, se firmó un contrato para la concesión de un territorio de tres mil acres (unas mil doscientas hectáreas) cerca del río Trinity en Texas.

La única obligación de los colonos era la de establecer cualquier tipo de construcción en las parcelas asignadas antes del 1 de julio de 1848. Lo que Cabet no tuvo claro al principio, aunque se dio cuenta con el paso del tiempo, es que no habría podido construir Icaria en este territorio ya que obtuvo la concesión de un territorio que era prácticamente un tablero de ajedrez: cada parcela de terreno confinaba, por un lado, con una parcela del mismo tamaño de propiedad de Peters \& C.; y por el otro, con una parcela doble que el Estado de Texas no cedió a la compañía. Era evidente que las diferentes parcelas concedidas a los icarianos no permitían la edificación de una comunidad tal y como estaba descrita en el Vyage $^{12}$.

Después de unos meses de propaganda intensa, organización y discusiones entre los partidarios de la emigración y las facciones que querían continuar la lucha en Francia, a principio de 1848 la primera vanguardia estaba lista para salir. El objetivo de esta primera vanguardia era el de alcanzar las tierras asignadas a la comunidad e instalar los primeros asentamientos. Cabet decidió no participar en este primer viaje, para poder coordinar desde París la salida de las siguientes expediciones.

\footnotetext{
${ }^{11}$ Etienne Cabet, "Allons en Icarie", Le Populaire, 9 de mayo de 1847.

12 Sutton, Les icariens, 45-48.
} 
El día 3 de febrero, la primera vanguardia salió del puerto de El Havre en dirección a Nueva Orleans con 65 fervientes icarianos. Entre ellos se encontraba el médico español Juan Rovira, cuyas cartas fueron publicadas en La Fraternidad en los días anteriores a la salida. Una vez que la primera vanguardia llegó al puerto de Nueva Orleans surgieron varios problemas. La noticia de la Revolución de febrero de 1848 en Francia minó la moral del grupo, ya que algunos plantearon la hipótesis de volver a Francia para participar en la rebelión. Se evitó esta posibilidad, pero se contribuyó a crear descontento entre los colonos.

A esto se añadieron los problemas para alcanzar este territorio, los fallos en el contrato firmado con Peters y la conformación de las parcelas cedidas. De todas formas, aunque desanimados por los problemas enfrentados, los colonos se pusieron a edificar las parcelas para cumplir el plazo de construcción y evitar que la compañía Peters y el estado de Texas se las quitaran. Al mismo tiempo, el fundador de la colonia se despreocupó totalmente de sus propios secuaces en ultramar para intentar satisfacer sus expectativas con la Revolución de 1848. Solamente el fracaso de la revolución y de los partidos demócratas y republicanos, añadido a los problemas a los que se estaban enfrentando en la comunidad, convencieron a Cabet a dedicarse aún más al proyecto icariano. Mientras tanto, la llegada de la segunda vanguardia no mejoró la situación de la colonia. Hay que poner énfasis en la presencia de otros dos españoles en esta expedición: Ignacio Montaldo y Candelaria, la mujer de Juan Rovira.

Los problemas a los que se enfrentaron los icarianos podían ser resueltos solamente con la llegada de "padre" Cabet. A pesar de la retórica de Cabet intentando justificar el fracaso, varios de los colonos decidieron abandonar el proyecto, algunos volviendo a Francia y otros se quedaron en Estados Unidos como ciudadanos. Entre los que abandonaron el sueño icariano estaba Juan Rovira que, desanimado por el fiasco, decidió quitarse la vida.

Los icarianos fieles a Cabet concluyeron que la única posibilidad de éxito era la de trasladar la comunidad a un lugar más adecuado. Lo encontraron en Nauvoo, una antigua colonia de mormones en Illinois abandonada en 1847. En marzo de 1849 los icarianos llegaron a la nueva Icaria con un renovado optimismo. La ferviente actividad de los icarianos permitió construir una colonia bastante parecida a la idea de comunidad que se encuentra en el Voyage y esta comenzó a prosperar. Se construyeron todo tipo de actividades y empezaron a comerciar con las comunidades contiguas a cambio de los bienes que no podían producir de forma autosuficiente. Los años que transcurrieron entre 1849-1855 fueron los más tranquilos y relativamente exitosos para la comunidad icariana.

En 1856 dentro de la comunidad surgió un movimiento en oposición a Cabet y hubo una primera escisión, debido especialmente a la actitud despótica de Cabet, que quería ejercer demasiado control sobre la comunidad, de forma similar a una dictadura. Cabet, expulsado por su propia comunidad, decidió fundar una Nueva Icaria en San 
Luis junto con algunos de sus más fieles seguidores. Pocos días después de trasladarse a San Luis, Cabet sufre un infarto y muere.

Como indica Sutton, la escisión de la colonia de Nauvoo y la muerte de Cabet marcaron el final de la fase más activa del comunismo icariano. Sin embargo, a lo largo de todo el siglo las comunidades que se inspiraban en la utopía cabetiana siguieron con diferentes experimentos nacidos de esta primera comunidad. Además de las primeras dos comunidades en Red River (Texas, 1848) y en Nauvoo (Illinois, 1849-1860), se produjeron experiencias similares en Cheltenhan (Missouri, 1858-1864), Corning, Adams County (Iowa, 1852-1878), Jeune Icarie (Iowa, 1878-1886), New Icaria (Iowa, 1878-1898) e Icaria Speranza (California, 1881-1886) ${ }^{13}$.

\section{EL BALANCE ENTRE UTOPÍA Y VOYAGE EN ICARIE}

El Viaje por Icaria ${ }^{14}$ es una obra extensa donde su autor describe minuciosamente la vida en Icaria, a través de la figura de Lord William Carisdall, un rico aristócrata inglés que decide visitar este lugar del que había oído hablar. En Icaria, Carisdall conoce a Valmor y su familia, que serán sus guías en el país y le ilustrarán en todos los aspectos de la vida en el país. Icaria es un país totalmente proporcionado, constituido por cien provincias, formadas por diez comunas cada una. La ciudad de Icaria, donde se desarrolla la mayor parte de la estancia de Carisdall en el país, es la capital y destaca en su planificación urbana. La única diferencia entre Icaria y las demás ciudades de este país ideal es la presencia del Palacio Nacional que se ubica en una pequeña isla en el río que atraviesa la ciudad.

La sociedad icariana es totalmente igualitaria, pues se han eliminado las fuentes principales de la desigualdad: el dinero y la propiedad privada. La República controla toda la producción y distribución de los bienes, que están depositados en enormes almacenes públicos. Las condiciones de trabajo son iguales para todos. De hecho, los trabajos más fatigosos e insalubres los realizan máquinas que mejoran la producción y la calidad del trabajo. En Icaria, se da mucha importancia al cultivo de la tierra y cada uno de los habitantes tiene la obligación de residir y trabajar durante un periodo de dos años en las granjas que están fuera de la ciudad para aprender a cultivar y contribuir en el sostenimiento del país. De cualquier manera, cada ciudadano puede elegir su oficio y si no le gusta o no es necesario a la comunidad puede aprender otro.

Dado que se ha abolido el dinero, ningún trabajador recibe un sueldo. Sin embargo, cada uno de los habitantes recibe lo que necesita, pero sin lujos o bienes superfluos. Uno de los aspectos que Carisdall destaca en su descripción es el sistema educativo. En Icaria se da muchísima importancia a la fase del crecimiento de los

13 Boris Blick, "Life in New Icaria, Iowa: a Nineteenth Century Utopian Community", The Annals of Iowa 42-3 (1974): 198-204.

${ }^{14}$ Para este estudio he utilizado la edición en castellano publicada en 1848, traducida por Francisco José de Orellana y Narcís Monturiol. 
jóvenes. Al principio de la educación, hay siempre un entrenamiento físico según la máxima de la mens sana in corpore sano. Los niños empiezan su formación a los cinco años, hasta los diecisiete para las chicas y un año más para los chicos.

Ambos sexos reciben una instrucción muy variada: Humanidades y Ciencias son las asignaturas principales, aunque tienen gran importancia también la música y las artes. Después de unos años de enseñanza genérica, los icarianos reciben una educación más específica que tiene por objeto el aprendizaje teórico y práctico de una profesión elegida por el alumno. Todos estos estudios duran hasta los veinte años, pero la formación es continua a lo largo de la vida porque el aprendizaje es importante también para los adultos. De hecho, cuando termina la jornada laboral de seis horas gran parte del tiempo libre se dedica al aprendizaje.

En cuanto a la organización social y política, todas las leyes de Icaria tienen por objeto establecer la máxima igualdad entre sus conciudadanos que tienen iguales derechos y deberes. En este país el pueblo es soberano y mediante sus representantes han creado una constitución que gobierna los aspectos principales de la vida política. Todo funcionario público tiene una carga electiva y temporal y todos los icarianos pueden ser electos. La Representación Popular se compone de dos mil diputados, que renuevan su cargo cada dos años. El órgano ejecutivo está formado por un presidente y cuarenta y cinco miembros, elegidos cada dos años, y está subordinado a la representación popular. Cada provincia y cada partido tiene sus asambleas populares donde cada ciudadano puede discutir activamente las decisiones que se toman.

Cabet en su texto desarrolla cada uno de los aspectos relevantes de la sociedad dedicando uno o más capítulos a cada uno de ellos: en la primera parte del texto, dibuja un relato minucioso sobre sanidad, agricultura, religión, industrias, trabajo, prensa, ocio, colonias, etc. Mientras que la segunda parte del texto, se dedica al proceso de formación de la sociedad icariana. Uno de los amigos icarianos de Lord Carisdall es Dinaros, un joven historiador que describe la fundación de Icaria. Esta nación fue creada en 1782, el año de la Gran Revolución. Antes de este acontecimiento, la isla estaba dominada por una dictadura. En 1772, el último dictador Corug fue destituido por la reina Cloramide y su esposo Lixdox. Estos nuevos tiranos, descritos como esclavistas, fomentaron una rebelión encabezada por Icar. Esta rebelión triunfó en 1782 cuando Icar fue nombrado dictador por todo el pueblo.

Con el nombramiento de Icar comienza un periodo de transición que precede la constitución definitiva del sistema icariano. La fase de transición tenía que durar unos cincuenta años, pero se cumplieron los objetivos antes de tiempo reduciendo el periodo transitorio a treinta años, por lo que la comunidad de bienes fue instaurada íntegramente en 1812. Ni la muerte imprevista de Icar en 1798 pudo parar este proceso. El objetivo principal de la fase transitoria era el de acostumbrarse gradualmente al nuevo sistema, ya que un cambio radical habría comportado numerosos problemas. Durante esta fase, la propiedad privada seguía existiendo y el trabajo era libre y no 
obligatorio. La desigualdad entre los icarianos iba disminuyendo poco a poco y se empezaba a instruir a los jóvenes según los principios icarianos.

\section{EL VOYAGE EN ICARIEY SUS INFLUENCIAS}

En muchos casos, la historiografía moderna considera Cabet como un personaje menor y destacan su poca originalidad, ya que parece haber imitado varias obras de teóricos y pensadores precedentes. Dentro de este panorama, es evidente la influencia de Las aventuras de Telémaco (1699) de François Fénelon que fue leído por Cabet cuando todavía frecuentaba el liceo en Dijon ${ }^{15}$. En esta obra, tal y como hace Cabet, el autor describe sociedades modelo donde no existe la guerra, los bienes son colectivos y la sociedad se caracteriza por la sobriedad y la ausencia de lujos y riquezas superfluas.

Otra de las obras que probablemente han contribuido a la elaboración del sistema icariano es el Código de la naturaleza (1755) de Étienne-Gabriel Morelly, donde el autor revela, después de una larga disertación, las leyes fundamentales que cortarían de raíz los vicios y todos los males de la sociedad: la abolición de la propiedad privada, la obligación del estado de sustentar sus habitantes y de los ciudadanos de aportar una contribución a la sociedad ${ }^{16}$ según sus capacidades.

Seguramente se pueden encontrar similitudes entre la Icaria cabetiana y la ciudad de París que describe Louis-Sébastien Mercier en su ucronía Año dos mil cuatrocientos cuarenta (1771), que cuenta la historia de un hombre que, a finales del siglo XIX, se duerme para poder despertarse en París 650 años después. Mercier describe con multitud de detalles los jardines, los edificios adornados con flores, los hospitales, las bibliotecas y los teatros que recorre el protagonista. La Francia de la historia había logrado realizar todos los ideales demócratas e ilustrados que según el autor se irían realizando con el progreso de la sociedad. Es evidente que ambos autores confían en el progreso como factor de realización de un modelo de sociedad mejor.

La estancia de Cabet en Londres favoreció su contacto con Robert Owen que comparte sus mismos principios, como confiesa el pensador francés. Según Owen, gracias a la educación, la sociedad podría garantizar la felicidad personal y el bien común de todos los ciudadanos. Es probable que Owen haya tenido una cierta influencia en la elaboración del sistema icariano, dado que mientras Cabet todavía tenía que empezar a elaborar sus hipótesis, Owen ya había experimentado varios modelos de comunidad. A pesar de la experiencia del empresario galés, Cabet critica a Owen, acusándole de perder su tiempo en comunidades experimentales demasiado pequeñas para que puedan triunfar.

\footnotetext{
${ }^{15}$ Sutton, Les Icariens, 18-20.

16 Albert Soboul. "Ilustración, crítica social y utopía durante el siglo XVIII francés", en Historia general del socialismo. De los orígenes a 1875, dir. Jacques Droz (Barcelona: Destino, 1984), 102-193, 138 y ss.
} 
La última influencia, y quizás la más problemática, es la de Babeuf y del neobabuvismo. Étienne Cabet conocía perfectamente la Conspiración de los Iguales malograda por Babeuf en 1797. En la base del pensamiento babouvista se encontraba la creencia de que no se podía instaurar una verdadera democracia sin la igualdad a nivel económico. Este movimiento revolucionario es considerado muy importante dado que por primera vez aparece la idea comunista en el contexto político. El pasado de Cabet en la Carbonería y su cercanía a las ideas de Babeuf y Buonarroti, lo trasformaron en objetivo fácil de las acusaciones de neobabuvismo.

Dentro de este heterogéneo y múltiple panorama de influencias, la Utopía de Tomás Moro tiene un lugar especial ya que, como cuenta el mismo Cabet, «su idea fundamental me produjo una impresión tal que cerré el libro sin querer acordarme de sus detalles, a fin de meditar seriamente sobre esta idea de Comunidad que nunca había tenido tiempo para profundizar, estando por otra parte dominado, a la par que todo el mundo, por la ciega prevención que proscribe a la Comunidad como una quimera ${ }^{17} »$. Moro es el único autor que Cabet nombra abiertamente en el Voyage en Icarie como una de las obras que lo han influenciado.

A pesar de esto, la información relativa a la lectura de Utopía por parte de Cabet no es del todo cierta. En un artículo publicado sobre la relación entre Moro y $\mathrm{Cabet}^{18}$, Desroche constata que cuando Cabet habla de Moro y de su influencia en la publicación del Voyage en Icarie lo hace con algunas incongruencias: en la parte citada al final de la obra, Cabet razona sobre su proyecto de publicar un libro sobre la Comunidad y considera la lectura de la Utopía como el factor determinante para convencerlo de la bondad del proyecto. Sin embargo, en Comment je suis communiste et mon credo communiste, Cabet afirma que todo el proyecto de la Comunidad es fruto de su propia inspiración y que sólo después de haber terminado el Voyage decide buscar contrapruebas en la lectura de varios filósofos y pensadores, entre ellos Moro y su Utopía.

Esta incongruencia, según Desroche, es la prueba que Cabet utiliza Moro como una argucia para alejar las acusaciones de sedición, a las que ya había tenido que enfrentarse en el pasado. Hay que recordar que Cabet acababa de volver de un exilio por culpa de unos artículos publicados en Le Populaire y no habría podido defenderse fácilmente de una imputación de neobabuvismo, owenismo u otras doctrinas consideradas subversivas. En este sentido era mucho mejor presentar su obra bajo el ala protectora de alguien católico y moralmente irreprochable, como el Canciller inglés, que de alguien ateo y anárquico como Babeuf.

Hay otras razones para esta propensión de Cabet hacia Moro. La primera y la más evidente es el género literario. Evidentemente, Cabet habría podido escribir un tratado de filosofía política exponiendo sus ideas, pero elige publicar una novela

${ }^{17}$ Etienne Cabet, Viaje por Icaria, (Barcelona: Editorial La Oriental, 1848), 233.

18 Henri Desroche, "De Thomas More a Etienne Cabet", Moreana 31-32 (1971): 215-219. https://doi.org/10.3366/more.1971.8.3-4.27 
describiendo un viaje imaginario: seguramente Cabet fue atraído por la idea general de la Utopia de Moro, pero sobre todo por la forma que permite la recepción de las ideas fundamentales a un público más extenso y variado como, por ejemplo, las mujeres.

Sí, compongo una novela para explanar un sistema social, político y filosófico, porque estoy profundamente convencido de que es la forma más sencilla, más natural y más inteligible para hacer comprender el sistema más difícil y complicado; porque no es mi ánimo el escribir sólo para las personas científicas, sino para todo el mundo; porque deseo vivamente que mi obra sea leída por la MUJERES, que serían unos apóstoles los más a propósito para persuadir si su alma generosa estuviese perfectamente convencida de lo que constituye el verdadero interés de la Humanidad; porque no quiero imitar a los economistas y sus secuaces, los que, como dice Condorcet, malograron a menudo sus ideas por el abuso de las frases científicas: quizá me engañe, pero esta forma, de la que por otra parte me sugirió la idea la Utopía, me parece preferible a todas aquellas que han escogido los modernos escritores para tratar asuntos análogos... me es, sin duda, necesaria la indulgencia de mis lectores, sobre todo por lo que toca a la parte novelesca; pero se concebirá fácilmente que esta parte no es más que un accesorio al cual he debido hacer ocupar el menos espacio posible ${ }^{19}$.

Otra de las razones evidentes de la utilización -verdadera o ficticia- de Utopía por parte de Cabet como fuente de inspiración para la elaboración de su texto hay que relacionarlo con la religión. En muchos de sus textos publicados después del Voyage, Cabet anuncia su intención de volver a un cristianismo de los orígenes donde instaurar una comunidad de bienes basada en la fraternidad y la igualdad entre todos. De hecho, según Cabet, la comunidad se habría podido establecer mucho antes si las primeras comunidades religiosas no se hubieran corrompido malinterpretando el mensaje de Jesús.

El mensaje icariano está estrictamente ligado al cristianismo, como demuestra el manifiesto de la fundación de Icaria -el famoso artículo Allons en Icarie- donde hay una comparación entre los que pertenecen a la primera Vanguardia con los «nuevos Hebreos» que la abandonan

la Casa de esclavitud para ir a conquistar una Tierra prometida, un nuevo Paraíso terrenal, perseguidos como Jesús y sus discípulos por nuevos Fariseos, retiremos como ellos al desierto, en una tierra virgen, limpia de toda mancha que nos ofrecerá todos los tesoros de su fecundidad! Nuevos Cruzados, vámonos a una tierra Santa, no para desenterrar una tumba, y si para construir la cuna de una nueva Jerusalén o de una ciudad perfecta! [...] Nuevos Misionistas, vamos a predicar, o más bien, a realizar la Fraternidad, inscribiéndola en nuestras leyes y en nuestras instituciones, así como en nuestros monumentos y sobre todo en nuestros corazones ${ }^{20}$.

\footnotetext{
${ }^{19}$ Cabet, Viaje por Icaria, 239.

${ }^{20}$ Cabet, "Allons on Icarie".
} 
En esta particular visión sectaria, Cabet era aclamado como le père ("el padre") y para sus secuaces era «el Reformador del Siglo XIX que fundará el reinado de Dios sobre la tierra». En otro artículo aparecido en La Fraternidad resulta indiscutible el valor de la religión en la doctrina icariana, ya desde el título, «La Comunidad es el Cristianismo», y en que Jesucristo es designado como el primer comunista. Es indiscutible que para un proyecto concebido de tal manera, la figura de Tomás Moro se adapta perfectamente al papel de patrocinador. Moro en este sentido representa el cristianismo más puro y sincero, ejemplo de rectitud frente a la corrupción de la Iglesia que tanto criticaba Cabet.

\section{CONCLUSIÓN}

Es difícil establecer cuál es la influencia de la Utopía de Tomás Moro en Étienne Cabet, sobre todo porque las indicaciones que el pensador francés nos da al respecto son incongruentes. No hay certeza de que Cabet haya leído la Utopía en inglés como confiesa en el capítulo conclusivo del Voyage en Icarie, en especial porque cuando llegó a Londres exiliado su conocimiento del idioma parece que era bastante escaso.

Es posible que hubiera leído la Utopía incluso antes de llegar a Inglaterra, como dice una nota de la biografía escrita por Proudhommeaux; según la cual habría recibido una edición en francés que se publicó en los años 30 del siglo XIX, basada en una primera versión de la obra en lengua francesa de 1715. De todas formas, la falta de conocimiento de la obra utópica por excelencia por parte de Cabet es bastante improbable, solo falta cuantificar qué tipo de influencia ha tenido en la elaboración del Voyage y en la sucesiva experiencia americana.

Está claro que las dos obras son similares en muchos aspectos, sobre todo en las ideas generales y en la forma de expresarlas, pero en el Voyage en Icarie se desarrollan más en profundidad varios aspectos prácticos de la vida comunitaria, añadiendo elementos típicos de la sociedad del siglo XIX, fruto del progreso industrial. Además, una prueba incuestionable del influjo moreano en Cabet es que su experiencia en Londres marca un antes y un después en su actividad política, porque cuando vuelve de su exilio ya no es el escritor y político rebelde que era, con lazos con sociedades secretas y el deseo de derrocar a la monarquía, sino un pensador utópico que quiere cambiar el mundo sin violencia a través de una comunidad basada en la fraternidad entre hombres y mujeres. Este cambio es fruto también de la lectura de Utopía, obra que seguramente incita a Cabet a investigar sobre este tema y a elaborar su propia propuesta.

Este breve trabajo evidencia la capacidad de Cabet de reinterpretar el utopismo de Moro en clave decimonónica, añadiendo una crítica al capitalismo y al papel revolucionario de la industria moderna. Cabet supo insertar la Utopía de Moro en el contexto de la sociedad industrial del siglo XIX confiriendo actualidad a una obra publicada trescientos años antes. Está claro que la difusión y el éxito de las doctrinas 
cabetianas en Francia y España contribuyeron a crear una nueva e inesperada popularidad al trabajo de Tomás Moro.

\section{BIBLIOGRAFÍA}

Blick, Boris, "Life in New Icaria, Iowa: a Nineteenth Century Utopian Community", The Annals of Iowa 42-3 (1974): 198-204.

Bravo, Gian Mario, Historia del socialismo, 1789-1848: el pensamiento socialista antes de Marx (Barcelona: Ariel, 1976).

Cabet, Etienne, Viaje por Icaria (Barcelona: La Oriental, 1848).

Desroche, Henri, "De Thomas More a Etienne Cabet”, Moreana 31-32 (1971): 215-219. https://doi.org/10.3366/more.1971.8.3-4.27

Engels, Friedrich, Del socialismo utópico al socialismo científico: Ludwig Feuerbach y el fin de la filosofía clásica alemana (San Sebastián: Equipo Editorial, 1968).

Johnson, Christopher H., Utopian Communism in France: Cabet and the Icarians, 1839-1851 (Londres: Cornell University Press, 1974).

Maluquer de Motes, Jordi, El socialismo en España 1833-1868 (Barcelona: Crítica, 1977).

Neusüss, Arnhelm, Utopía (Barcelona: Barral, 1971).

Marx, Karl, y Friedrich Engels, La ideología alemana (Montevideo: Pueblos Unidos, 1968).

Moro, Tomás, Utopía (Buenos Aires: Losada, 1999).

Prudhommeaux, Jules, Icarie et son fondateur Etienne Cabet (Ginebra: Slatkine-Megariotis, 1977).

Soboul, Albert. "Ilustración, crítica social y utopía durante el siglo XVIII francés", en Historia general del socialismo. De los orígenes a 1875, dir. Jacques Droz (Barcelona: Destino, 1984), 102-193.

Sutton, Robert P., Les icariens: the utopian dream in Europe and America (Chicago: University of Illinois Press, 1994). 
Recibido: 7 de mayo de 2017 Aprobado: 17 de octubre de 2017 